\title{
Caregiver food behaviours are associated with dietary intakes of children outside the child-care setting
}

\author{
Temitope O Erinosho ${ }^{1, *}$, L Beth Dixon ${ }^{2}$, Candace Young ${ }^{3}$, Laurie Miller Brotman ${ }^{4}$ and \\ Laura L Hayman ${ }^{5}$ \\ 'Department of Nutrition/Center for Health Promotion and Disease Prevention, University of North Carolina, \\ 700 Martin Luther King Jr. Blvd, 2nd Floor, Campus Box 7426, Chapel Hill, NC 27599-7426, USA: \\ ${ }^{2}$ Department of Nutrition, Food Studies and Public Health, New York University, New York, NY, USA: ${ }^{3}$ The Food \\ Trust, Philadelphia, PA, USA: ${ }^{4}$ School of Medicine, New York University, New York, NY, USA: ${ }^{5}$ Department of \\ Nursing, University of Massachusetts, Boston, MA, USA
}

Submitted 27 May 2011: Final revision received 29 February 2012: Accepted 20 April 2012: First published online 10 August 2012

\begin{abstract}
Objective: To evaluate whether food behaviours of parents are associated with children's dietary intakes outside the child-care setting, and to compare children's dietary intakes at home with foods and beverages consumed when they are at child-care centres.

Design: In 2005-2006, a survey was completed by parents of at least one child between 3 and 5 years old who attended group child-care centres. Surveys about nutrition practices were completed by centre directors. Research assistants observed foods and beverages consumed by children at lunchtime at the centres. Setting: Sixteen licensed group child-care centres in three underserved New York City communities (South Bronx, East/Central Harlem, Central Brooklyn) and the Lower East Side of Manhattan.

Subjects: Two hundred parents.

Results: Children were more likely to consume healthful foods including fruits or vegetables if parents reported purchasing food from produce stands/farmers' markets, shopped for frozen or canned fruits frequently and ate family meals or meals prepared at home daily. Children were more likely to consume less healthful foods such as French fries, or fruit drinks, more frequently if parents reported eating meals from fast-food or other restaurants at least once weekly, or if children ate while watching television. Types of foods and beverages offered to children at home (e.g. higher-fat milk, soft drinks and desserts) were less healthful than those offered at child-care centres.

Conclusions: Children's dietary intakes at home need to be improved. Parents need to understand the importance of providing home environments that support healthful food behaviours in children.
\end{abstract}

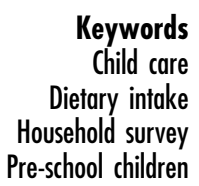

Keywords

Dietary intake

Household survey Pre-school children
Children's dietary behaviours are established in early childhood $^{(1)}$. During this critical stage of development, the majority of children under 6 years old (approximately $61 \%)$ in the USA share their time between the home and child-care settings ${ }^{(2)}$. Foods and beverages offered to and consumed by children in these settings play a significant role in children's overall health ${ }^{(3-6)}$.

At home, parents' food practices and family characteristics contribute to children's dietary intakes ${ }^{(7)}$. Studies of children and adolescents report that availability and accessibility of healthful foods such as fruits and vegetables at home is associated with greater consumption of these foods ${ }^{(8-10)}$. Frequent consumption of family meals at home is associated with higher intake of healthful foods in children ${ }^{(11-14)}$. In contrast, increased frequency of eating out, especially at fast-food restaurants, in children and adolescents is associated with higher intakes of sugarsweetened beverages and unhealthful foods such as full-fat dairy foods, red/processed meats and fried potatoes ${ }^{(15-18)}$. Eating food while watching the television (TV) is also associated with higher intakes of sugar-sweetened beverages and unhealthful foods such as pizza, salty snacks, chips and processed meats in children ${ }^{(19-22)}$.

Research studies about parents and children's dietary intakes have focused largely on school-aged children and adolescents $^{(23,24)}$. Few studies have examined the influence of parents' food behaviours on the dietary intakes of young children outside structured settings like child-care centres, particularly in New York City (NYC). Further research on this topic is needed to develop effective 
education campaigns and interventions to improve children's dietary intakes and reduce or prevent childhood obesity ${ }^{(25)}$.

The primary objective of the present study was to evaluate whether food behaviours of parents are associated with children's dietary intakes when they are not attending group child-care centres in NYC. Specifically, parents were asked about food purchasing behaviours (e.g. stores where household foods are purchased, ease and frequency of purchasing fruits and vegetables), food consumption behaviours (e.g. frequency of consuming family meals, meals prepared at home, meals from fastfood and other restaurants, eating while watching TV) and children's consumption of fruit, $100 \%$ fruit juice, vegetables, French fries, fruit drinks, soft drinks, desserts and snacks while in the presence of the caregiver. A secondary objective of the study was to determine whether children's intakes at home were more healthful than their intakes at the group child-care centres in NYC.

\section{Methods}

\section{Study design}

In 2005-2006, the NYC Department of Health and Mental Hygiene contracted with members of the research team to develop a survey on household food behaviours of parents of at least one child between 3 and 5 years old who attend child-care centres in NYC. In the study, the term 'parents' included biological parents and non-biological primary caregivers. This research was included as part of a larger study on the nutrition practices of forty licensed group child-care centres in NYC and in response to feedback from the directors stating that parents and caregivers of the children needed education about nutrition, especially with regard to what foods and beverages to feed their child. Details about the study methodology can be found elsewhere $^{(26,27)}$. Approval for the study procedures was obtained from the University Committee on Activities Involving Human Subjects at New York University.

\section{Assessment of parents' bebaviours and children's dietary intakes at bome}

Health professionals at the NYC Department of Health and Mental Hygiene and researchers at New York University developed survey questions about food purchasing and food consumption behaviours of parents and their families. Food purchasing behaviours included types of stores where household foods were purchased (supermarkets, small corner store/bodega, restaurants, discount stores, produce stand/farmers' market, other), ease of purchasing fruits and vegetables (very difficult, somewhat difficult, not very difficult) and frequency of purchasing fresh, frozen or canned fruits and vegetables (every day, a few times/week, 1 time/week, never). Food consumption behaviours included frequency of consuming family meals, meals prepared at home, meals from fastfood restaurants such as McDonalds or Wendy's and meals from other types of restaurants such as Italian, Chinese buffet, Mexican or Caribbean (every day, 4-6 d/week, 2-3 d/week, only on Sundays or $1 \mathrm{~d} /$ week, never). Parents were also asked about whether their children ate food while watching TV (yes, no).

To assess children's dietary intakes at home, parents were asked about their children's frequency of consuming fresh, canned or frozen fruits, $100 \%$ fruit juice (e.g. orange, apple, grapefruit juice), fresh, canned or frozen vegetables, fried potatoes (i.e. French fries, hash brown potatoes, tater tots), fruit drinks (e.g. Koolaid, Hi-C, Tang, Lemonade), non-diet soft drinks (e.g. Coke, Sprite, Pepsi), desserts (e.g. candy, cookies, ice cream, cake) and snacks (e.g. potato chips, Doritos, crackers) at home. Response categories were never, 1-2 times/week, 3-4 times/week, 5-6 times/week, 1 time/d and $>1$ time/d.

The Household Survey was developed in English and translated into Spanish. A graduate research assistant whose primary language was Spanish, and who was familiar with the target population, back-translated the Spanish survey to English to ensure that the Spanish translations were accurate and easy to understand. Content validity of both the English and Spanish versions of the survey was confirmed by nutrition faculty members and students at New York University's Department of Nutrition, Food Studies and Public Health.

\section{Assessment of children's dietary intakes at the child-care centre}

Two research assistants conducted site visits on a scheduled day that was convenient for child-care centres to administer a Director Survey and observe children's dietary intakes at the centres. The Director Survey was used to collect data about nutrition practices at child-care centres. The survey included questions about demographic characteristics of the centres; types of meals provided to children, places where foods and beverages are purchased and people in charge of purchasing foods and beverages; on-site food sources, such as availability of vending machines, kitchen and kitchen equipment, and cooks at the centres; and nutrition practices such as menu planning, selection of foods and beverages offered to children, availability of a health committee and person in charge of nutrition issues, and availability of nutrition-related activities for parents and children at the centres. Centre directors completed the Director Survey during face-to-face interviews with one research assistant. The current study analyses directors' responses about the selection of foods (e.g. fruits, vegetables, French fries) and beverages (e.g. milk, fruit juice) usually offered to children at the centres.

Dietary observations were conducted to assess children's dietary intakes at the child-care centres. In one pre-school classroom (3-4-year-olds) at each centre, the two research assistants selected six children at random to observe. 
Between 08.00 and 14.00 hours, the research assistants recorded all types and amounts of foods and beverages consumed by the children. In general, children ate two meals during this period: breakfast or morning snack (referred to as 'breakfast' hereafter because the foods and amounts served were very similar) and lunch. If types of beverages or foods were not obvious, teachers or food service staff members were asked to clarify. Data from the dietary observations were analysed to determine the actual selection of foods and beverages consumed by children during mealtimes at the centres.

\section{Study sample}

Directors of sixteen licensed child-care centres located in three District Public Health Office regions (four centres in the South Bronx, four centres in East and Central Harlem, five centres in Central Brooklyn) and in the Lower East Side of Manhattan (three centres) were contacted to participate in the study. These centres were selected because their directors had indicated interest in assisting with administering a survey to parents to assess caregiver behaviours during the initial phase of the larger study assessing nutrition practices at the forty childcare centres ${ }^{(27)}$. After obtaining written consent from the centre directors, the project coordinator explained the survey and obtained written consent from parents when they dropped off their child in the morning or when they arrived to pick up their child at the end of the day. Parents were asked to complete and return the Household Survey within a week to a box in a central location designated by directors of the centres. The Household Survey was distributed to 253 parents at the sixteen centres; $86 \%$ ( $n$ 218) of the parents completed and returned the survey. Surveys with missing responses to at least eight questions, out of a total of thirty-four questions, were excluded. In all, 200 surveys (i.e. fifty surveys per geographic region South Bronx, Harlem, Brooklyn, Lower East Side of Manhattan) were analysed. Parents who returned the Household Survey received a \$US 5 Pathmark gift certificate by mail as a thank you gift.

The Director Survey was administered to all centre directors. For the dietary observations, six children were selected at random in a classroom at each centre and observed during mealtimes. In all, dietary observation data were collected from ninety-six children who attended the sixteen child-care centres.

\section{Data analysis}

All data were coded and entered into the SPSS statistical software package version 16.0 (SPSS Inc.). Descriptive statistics were calculated for demographic characteristics, food behaviours of parents, parent-reported dietary intakes of children at home and observed dietary intakes of children at the child-care centre. Because of the small sample sizes for some of the categorical responses, parents' responses for food behaviours and children's dietary intakes at home were re-coded into two categories and cut-off points were selected according to the distribution of data across response categories and dietary recommendations ${ }^{(28)}$. Binary logistic regression models were created, and odds ratios and $95 \%$ confidence intervals were calculated to evaluate associations between parents' food behaviours and children's dietary intakes, controlling for parents' ethnicity and highest level of education completed. Two-sided $P$ values $<0.05$ were used to determine statistical significance.

The types of foods and beverages offered to children at home and at the child-care centres were also compared descriptively using data collected from the Household Survey, data collected from a survey of directors previously administered at the sixteen child-care centres as part of the larger study ${ }^{(27)}$, as well as $1 \mathrm{~d}$ of direct observation of ninety-six children's dietary intakes at lunchtime at all sixteen centres.

\section{Results}

\section{Demographic characteristics of parents}

Ninety-five per cent of the parents were women, $77 \%$ were 20 to 39 years old, and $54 \%$ were married or living with a partner (Table 1). The majority of parents were black or African-American (32\%) and Hispanic or Latino (55\%). About half (51\%) of parents reported that they had attended high school, $22 \%$ had received some

Table 1 Demographic characteristics of 200 parents of young children who attended sixteen group child-care centres in New York City, 2005-2006

\begin{tabular}{|c|c|c|}
\hline \multirow[b]{2}{*}{ Characteristic } & \multicolumn{2}{|c|}{ Parents (n 200) } \\
\hline & $n$ & $\%$ \\
\hline \multicolumn{3}{|l|}{ Gender } \\
\hline Female & 188 & $94 \cdot 5$ \\
\hline \multicolumn{3}{|l|}{ Age (years) } \\
\hline $20-29$ & 71 & $35 \cdot 9$ \\
\hline 30-39 & 82 & $41 \cdot 4$ \\
\hline $40-49$ & 31 & $15 \cdot 7$ \\
\hline$\geq 50$ & 14 & $7 \cdot 1$ \\
\hline \multicolumn{3}{|l|}{ Marital status } \\
\hline Single parent & 91 & $46 \cdot 0$ \\
\hline Married/living with partner & 107 & $54 \cdot 0$ \\
\hline \multicolumn{3}{|l|}{ Race/ethnicity } \\
\hline White & 1 & 0.5 \\
\hline Black/African-American & 63 & $31 \cdot 7$ \\
\hline Hispanic/Latino & 109 & $54 \cdot 8$ \\
\hline Asian & 23 & $11 \cdot 6$ \\
\hline Other & 3 & 1.5 \\
\hline \multicolumn{3}{|l|}{ Highest level of education completed } \\
\hline High school & 96 & $50 \cdot 5$ \\
\hline Some college & 41 & $21 \cdot 6$ \\
\hline \multirow[t]{2}{*}{ College degree/graduate school } & 53 & $27 \cdot 9$ \\
\hline & Mean & SD \\
\hline Number of persons residing in the household & $4 \cdot 18$ & $1 \cdot 19$ \\
\hline Number of children residing in the household & $2 \cdot 12$ & $1 \cdot 02$ \\
\hline
\end{tabular}


college education and $28 \%$ had completed a college degree. Parents reported an average of four persons residing in each household.

\section{Food behaviours of parents}

All parents reported that they purchased food for their household from supermarkets, $68 \%$ also purchased food from corner stores or bodegas, and about half of caregivers purchased food from produce stands or farmers' markets (Table 2). Approximately one-third of parents also reported purchasing food for their household from restaurants and discount stores. The majority of parents reported that they did not find it very difficult to purchase fresh fruits and vegetables for their household. Twothirds of parents said that they purchased fresh fruits and vegetables daily or a few times weekly, and half reported that they also purchased frozen or canned vegetables once weekly or more frequently.

Two-thirds of parents reported that their families usually ate meals together every day (Table 2). Thirtynine per cent reported that their families usually ate meals prepared at home every day, but at least $70 \%$ of parents reported that their families ate meals from fastfood or other restaurants once weekly. About half of parents reported that their children ate food while watching TV.

Table 2 Food behaviours of 200 parents of young children who attended sixteen group child-care centres in New York City, 2005-2006

\begin{tabular}{|c|c|c|}
\hline & \multicolumn{2}{|c|}{ Parents $(n$ 200) } \\
\hline & $n$ & $\%$ \\
\hline \multicolumn{3}{|c|}{ Do you buy food for your household at ('yes' responses) ${ }^{\star}$} \\
\hline Supermarket & 199 & $100 \cdot 0$ \\
\hline Bodega/corner store & 135 & $67 \cdot 8$ \\
\hline Restaurant & 72 & $36 \cdot 2$ \\
\hline Produce stand/farmers' market & 97 & $48 \cdot 5$ \\
\hline Discount store & 74 & $37 \cdot 2$ \\
\hline Other & 14 & $7 \cdot 0$ \\
\hline \multicolumn{3}{|c|}{ How difficult is it to purchase fresh fruits and vegetables } \\
\hline Very difficult & 7 & $3 \cdot 6$ \\
\hline Somewhat difficult & 40 & $20 \cdot 3$ \\
\hline Not very difficult & 150 & $76 \cdot 1$ \\
\hline \multicolumn{3}{|c|}{ Frequency of purchasing fresh fruits and vegetables } \\
\hline Daily & 29 & $14 \cdot 9$ \\
\hline A few times/week & 97 & $49 \cdot 7$ \\
\hline 1 time/week & 59 & $30 \cdot 3$ \\
\hline$<1$ time/week & 10 & $5 \cdot 1$ \\
\hline \multicolumn{3}{|c|}{ Frequency of purchasing frozen or canned fruits and vegetables } \\
\hline Daily & 2 & $1 \cdot 0$ \\
\hline A few times/week & 40 & $20 \cdot 4$ \\
\hline 1 time/week & 59 & $30 \cdot 1$ \\
\hline$<1$ time/week & 69 & $35 \cdot 2$ \\
\hline Never & 26 & $13 \cdot 3$ \\
\hline \multicolumn{3}{|l|}{ Frequency of consuming family meals } \\
\hline Every day & 134 & $67 \cdot 0$ \\
\hline $4-6 \mathrm{~d} /$ week & 33 & $16 \cdot 5$ \\
\hline $2-3 d /$ week & 28 & $14 \cdot 0$ \\
\hline Only on Sundays & 4 & $2 \cdot 0$ \\
\hline Never & 1 & 0.5 \\
\hline \multicolumn{3}{|c|}{ Frequency of consuming meals prepared at home } \\
\hline Every day & 76 & $38 \cdot 8$ \\
\hline $4-6 \mathrm{~d} /$ week & 44 & $22 \cdot 4$ \\
\hline $2-3 \mathrm{~d} /$ week & 22 & $11 \cdot 2$ \\
\hline Only on Sundays & 22 & $11 \cdot 2$ \\
\hline Never & 32 & $16 \cdot 3$ \\
\hline \multicolumn{3}{|c|}{ Frequency of consuming meals from fast-food restaurants } \\
\hline Every day & 1 & 0.5 \\
\hline $4-6 \mathrm{~d} /$ week & 3 & $1 \cdot 5$ \\
\hline $2-3 d /$ week & 22 & $11 \cdot 1$ \\
\hline $1 \mathrm{~d} /$ week & 142 & $71 \cdot 4$ \\
\hline$<1 \mathrm{~d}$ or never & 31 & $15 \cdot 6$ \\
\hline \multicolumn{3}{|c|}{ Frequency of consuming meals from other restaurants } \\
\hline Every day & 1 & 0.5 \\
\hline $4-6 \mathrm{~d} /$ week & 3 & $1 \cdot 5$ \\
\hline $2-3 \mathrm{~d} /$ week & 19 & $9 \cdot 7$ \\
\hline $1 \mathrm{~d} /$ week & 137 & $70 \cdot 3$ \\
\hline$<1 \mathrm{~d}$ or never & 35 & $17 \cdot 9$ \\
\hline
\end{tabular}

*A farmers' market is an outdoor food market where local farmers sell their produce directly to the public. Compared with small corner stores/bodegas, produce stands and farmers' markets are known for carrying fresh, locally grown produce, especially fruits and vegetables. 
Food behaviours of parents associated with children's dietary intakes

Purchasing food from produce stands or farmers' markets and frequency of purchasing frozen or canned fruits and vegetables were associated with children's consumption of fruits and vegetables. The odds of children consuming fruits $(\mathrm{OR}=2 \cdot 32,95 \% \mathrm{CI} 1 \cdot 24,4 \cdot 35)$ and vegetables $(\mathrm{OR}=2 \cdot 52,95 \% \mathrm{CI} 1 \cdot 31,4 \cdot 86)$ at least once daily was more than twice as high if parents reported purchasing food from produce stands or farmers' markets, compared with children whose parents did not purchase food from produce stands or farmers markets. On the other hand, the odds of children consuming fruits at least once daily decreased by $61 \%(\mathrm{OR}=0 \cdot 39,95 \%$ CI $0 \cdot 18,0 \cdot 85)$ if parents reported that they purchased frozen or canned fruits and vegetables for their household $\leq 1$ time/week, compared with children whose parents purchased frozen or canned fruits and vegetables a few times per week or daily. Purchasing food from corner stores or bodegas and restaurants, and self-reported ease of purchasing fruits and vegetables were not associated with children's intake of fruits and vegetables.

Consumption of meals prepared at home was associated with children's intakes of fruits and vegetables (Table 3). The odds of children consuming fruits and vegetables decreased by $61 \%$ and $67 \%$, respectively, if parents reported that their families ate meals prepared at home $\leq 6 \mathrm{~d}$ /week, compared with children whose parents reported eating meals prepared at home daily. Also, the odds of children consuming 100\% fruit juice at least once daily decreased by $48 \%$ if parents reported eating family meals $\leq 6 \mathrm{~d}$ /week compared with children whose families ate meals together on a daily basis.

Consumption of meals from fast-food and other restaurants was associated with children's intake of French fries. The odds of children consuming French fries at least once weekly decreased by $76 \%$ and $69 \%$, respectively, if parents reported that their families never ate meals from fast-food and other restaurants, compared with children whose parents reported eating meals from fast-food and other restaurants $\geq 1$ time/week. The odds of children consuming $100 \%$ fruit juice at least once daily decreased by $53 \%$ if parents reported that their children ate while watching TV. The odds of children consuming fruit drinks, desserts and snacks $\geq 3$ times/week increased by more than 100 to $200 \%$ if parents reported that their children ate while watching TV.

\section{Children's dietary intakes at bome v. at group child-care centres}

The majority of parents reported that children consumed high-fat milk such as whole or $2 \%$ milk at home whereas most child-care centres offered low-fat milk such as $1 \%$ or skimmed milk to children (Table 4). Almost all parents and all child-care centres offered fruits, 100\% fruit juice and vegetables to children. Seventy-seven per cent of parents reported that children consumed fruit drinks at home, and $23 \%$ said their children consumed fruit drinks $\geq 5$ times/week. In contrast, none of the centres reported providing fruit drinks to children. Half of the parents reported children consumed soft drinks at home, and $11 \%$ reported that their children drank soft drinks $\geq 5$ times/week. None of the child-care centres provided soft drinks to children. The majority of parents reported that children consumed French fries, desserts and snacks at home, but only a few said their children ate these foods $\geq 5$ times/week. Only one centre offered French fries to children for lunch on the day of dietary observations; although none of the centres offered desserts or snacks for lunch, a few centres offered these foods at the morning meal (two centres offered desserts like pudding, three centres offered snacks like crackers).

\section{Discussion}

In the present study, parents' behaviours related to food purchasing and food consumption were associated with reported dietary intakes of young children outside group child-care centres in NYC. First, children were more likely to consume healthful foods and beverages (e.g. fruits, vegetables, $100 \%$ fruit juice) if parents reported that they purchased food from produce stands or farmers' markets, shopped for frozen or canned fruits and vegetables frequently and ate family meals or meals prepared at home daily. These findings are consistent with prior studies of older children and adults that showed higher intakes of fruits and vegetables were associated with easy access to food outlets, including farmers' markets that carry large selections of fresh fruits and vegetables ${ }^{(29-35)}$, availability of fruits and vegetables at home ${ }^{(8-10,17)}$ and regular consumption of family meals ${ }^{(12,14)}$ and meals prepared at home ${ }^{(36)}$.

Second, children were more likely to consume unhealthful foods and sugar-sweetened beverages (e.g. French fries, desserts, sweet and salty snacks, fruit drinks) if parents reported their families ate meals from fast-food or other restaurants at least once weekly or if children ate food while watching TV. Eating out at fast-food or other restaurants is prevalent among young children in the USA $^{(37-39)}$. Meals and snacks based on foods prepared away from home tend to be higher in energy, total fat and saturated fat than foods prepared at home ${ }^{(40,41)}$. Studies show that eating out, especially at fast-food restaurants, is associated with decreased intakes of healthful foods, including fruits, vegetables and low-fat dairy foods, and increased intakes of unhealthful foods such as hamburgers, fried potatoes, soft drinks and sugar-sweetened beverages $^{(15,16,18,42)}$. Similarly, eating while watching TV is associated with eating less healthful foods like pizza, salty snacks, soda, red and processed meat, lower intakes of fruit, vegetables, grains and Ca-rich foods ${ }^{(21,22)}$ and decreased sensitivity to internal cues of satiety ${ }^{(43)}$. 
Table 3 Associations between children's dietary intakes at home and selected food behaviours, New York City, 2005-2006

\begin{tabular}{|c|c|c|c|c|c|c|c|c|c|c|}
\hline \multirow[b]{2}{*}{$\begin{array}{l}\text { Children's dietary } \\
\text { intakes }\end{array}$} & \multicolumn{2}{|c|}{ Family meals: $\leq 6 \mathrm{~d} /$ week $^{*}$} & \multicolumn{2}{|c|}{$\begin{array}{l}\text { Home-prepared meals: } \\
\leq 6 \mathrm{~d} / \text { weekt }\end{array}$} & \multicolumn{2}{|c|}{$\begin{array}{c}\text { Meals at fast-food restaurants: } \\
\text { never }\end{array}$} & \multicolumn{2}{|c|}{$\begin{array}{l}\text { Meals at other types of } \\
\text { restaurants: never§ }\end{array}$} & \multicolumn{2}{|c|}{ Eating while watching TV\| } \\
\hline & OR & $95 \% \mathrm{Cl}$ & OR & $95 \% \mathrm{Cl}$ & OR & $95 \% \mathrm{Cl}$ & OR & $95 \% \mathrm{Cl}$ & OR & $95 \% \mathrm{Cl}$ \\
\hline \multicolumn{11}{|l|}{ Fruit } \\
\hline$<1$ time $/ \mathrm{d}$ & 1.00 & - & 1.00 & - & 1.00 & - & 1.00 & - & 1.00 & - \\
\hline$\geq 1$ time/d & 0.62 & $0 \cdot 32,1 \cdot 18$ & 0.39 & $0.21,0.72$ & 0.83 & $0 \cdot 36,1 \cdot 88$ & 1.98 & $0.90,4.36$ & 0.89 & $0.49,1.63$ \\
\hline \multicolumn{11}{|l|}{$100 \%$ fruit juice } \\
\hline$<1$ time/d & 1.00 & - & 1.00 & - & $1 \cdot 00$ & - & 1.00 & - & 1.00 & - \\
\hline$\geq 1$ time/d & 0.52 & $0.28,0.97$ & 0.65 & $0 \cdot 35,1 \cdot 20$ & $1 \cdot 01$ & $0 \cdot 46,2 \cdot 24$ & 1.93 & $0.85,4.40$ & 0.47 & $0.25,0.85$ \\
\hline \multicolumn{11}{|l|}{ Vegetables } \\
\hline$<1$ time/d & 1.00 & - & 1.00 & - & 1.00 & - & 1.00 & - & 1.00 & - \\
\hline$\geq 1$ time/d & 0.60 & $0 \cdot 30,1 \cdot 20$ & 0.33 & $0.17,0.62$ & 0.91 & $0 \cdot 39,2 \cdot 12$ & 1.65 & $0.76,3.62$ & 0.72 & $0 \cdot 39,1 \cdot 34$ \\
\hline \multicolumn{11}{|l|}{ French fries } \\
\hline Never & 1.00 & - & 1.00 & - & 1.00 & - & 1.00 & - & 1.00 & - \\
\hline$\geq 1$ time/week & $1 \cdot 19$ & $0.48,2.95$ & 1.46 & $0.62,3.41$ & 0.24 & $0.09,0.60$ & 0.31 & $0 \cdot 12,0 \cdot 81$ & $1 \cdot 49$ & $0.65,3.42$ \\
\hline \multicolumn{11}{|l|}{ Fruit drinks } \\
\hline$\leq 2$ times/week & $1 \cdot 00$ & - & $1 \cdot 00$ & - & $1 \cdot 00$ & - & $1 \cdot 00$ & - & $1 \cdot 00$ & - \\
\hline$\geq 3$ times/week & 0.73 & $0 \cdot 37,1 \cdot 45$ & 0.92 & $0 \cdot 48,1 \cdot 78$ & 0.42 & $0 \cdot 16,1 \cdot 12$ & $1 \cdot 28$ & $0.55,3.00$ & $2 \cdot 33$ & $1 \cdot 20,4 \cdot 51$ \\
\hline \multicolumn{11}{|l|}{ Soft drinks } \\
\hline Never & 1.00 & - & $1 \cdot 00$ & - & 1.00 & - & 1.00 & - & $1 \cdot 00$ & - \\
\hline$\geq 1$ time/week & $1 \cdot 03$ & $0.55,1.94$ & 1.54 & $0 \cdot 82,2 \cdot 88$ & 0.50 & $0 \cdot 22,1 \cdot 16$ & 0.94 & $0.42,2 \cdot 07$ & 0.72 & $0 \cdot 39,1 \cdot 30$ \\
\hline \multicolumn{11}{|l|}{ Desserts } \\
\hline$\leq 2$ times/week & $1 \cdot 00$ & - & $1 \cdot 00$ & - & 1.00 & - & 1.00 & - & $1 \cdot 00$ & - \\
\hline$\geq 3$ times/week & $1 \cdot 32$ & $0 \cdot 70,2 \cdot 45$ & $1 \cdot 26$ & $0 \cdot 67,2 \cdot 35$ & 0.68 & $0.30,1.55$ & $1 \cdot 20$ & $0.54,2.66$ & $2 \cdot 84$ & $1 \cdot 52,5 \cdot 30$ \\
\hline \multicolumn{11}{|l|}{ Snacks } \\
\hline$\leq 2$ times/week & 1.00 & - & $1 \cdot 00$ & - & 1.00 & - & 1.00 & - & $1 \cdot 00$ & - \\
\hline$\geq 3$ times/week & 0.84 & $0.42,1.68$ & $2 \cdot 02$ & $1 \cdot 00,4 \cdot 07$ & 0.76 & $0 \cdot 32,1 \cdot 84$ & 0.88 & $0 \cdot 37,2 \cdot 11$ & $3 \cdot 20$ & $1 \cdot 59,6 \cdot 41$ \\
\hline
\end{tabular}

\section{TV, television.}

*Reference category: frequency of consuming family meals daily.

tReference category: frequency of consuming meals prepared at home daily.

TReference category: frequency of consuming meals from fast-food restaurants $\geq 1 \mathrm{~d} /$ week.

Reference category: frequency of consuming meals from other restaurants $\geq 1 \mathrm{~d} /$ week.

Reference category: 'no' responses to the question on eating during TV viewing. 
Table 4 Results from parent reports, child-care centre director reports and direct observations of children's dietary intakes at sixteen childcare centres in New York City, 2005-2006

\begin{tabular}{|c|c|c|c|c|c|c|c|c|}
\hline \multirow[b]{2}{*}{ Food group } & \multicolumn{2}{|c|}{$\begin{array}{l}\text { Household Survey } \\
\text { (200 parents) }^{*}\end{array}$} & \multicolumn{2}{|c|}{$\begin{array}{c}\text { Household Survey, } \\
\text { intake } \geq 5 \text { times/week } \\
(200 \text { parents }) \dagger\end{array}$} & \multicolumn{2}{|c|}{$\begin{array}{l}\text { Director Survey } \\
\text { (16 centres) } \ddagger\end{array}$} & \multicolumn{2}{|c|}{$\begin{array}{l}\text { Direct observations at } \\
\text { lunchtime ( } 16 \text { centres, } \\
96 \text { children observed)§ }\end{array}$} \\
\hline & $n$ & $\%$ & $n$ & $\%$ & $n$ & $\%$ & $n$ & $\%$ \\
\hline \multicolumn{9}{|l|}{ Milk } \\
\hline $1 \%$, skimmed & 97 & $57 \cdot 4$ & 58 & $34 \cdot 3$ & 13 & $81 \cdot 3$ & 13 & $81 \cdot 3$ \\
\hline Whole, $2 \%$ & 163 & $88 \cdot 6$ & 114 & $62 \cdot 0$ & 6 & $37 \cdot 5$ & 3 & $18 \cdot 7$ \\
\hline Fruits & 186 & $93 \cdot 9$ & 119 & $60 \cdot 1$ & 16 & $100 \cdot 0$ & 16 & $100 \cdot 0$ \\
\hline $100 \%$ fruit juice & 194 & $98 \cdot 5$ & 145 & $73 \cdot 7$ & 15 & $93 \cdot 8$ & $\|$ & - \\
\hline Vegetables & 188 & $95 \cdot 4$ & 103 & $52 \cdot 3$ & 16 & $100 \cdot 0$ & 16 & $100 \cdot 0$ \\
\hline French fries & 169 & $85 \cdot 4$ & 15 & $7 \cdot 5$ & $\|$ & - & 1 & $6 \cdot 3$ \\
\hline Fruit drinks & 150 & $77 \cdot 2$ & 45 & $23 \cdot 1$ & 1 & $6 \cdot 3$ & $\|$ & - \\
\hline Soft drinks & 95 & $49 \cdot 7$ & 21 & $11 \cdot 0$ & 0 & 0.0 & 0 & $0 \cdot 0$ \\
\hline Desserts & 186 & $94 \cdot 9$ & 48 & $24 \cdot 5$ & $\|$ & - & 0 & $0 \cdot 0$ \\
\hline Snacks & 183 & $92 \cdot 9$ & 33 & $16 \cdot 7$ & $\|$ & - & 0 & 0.0 \\
\hline
\end{tabular}

Centre directors were asked about the types of milk provided to children at their centres (not 3-5-year-olds, specifically). Some directors reported more than one milk type. Fruit juice consumption was observed at one centre (two children drank); however, the observers were unable to decipher whether it was $100 \%$ fruit juice or $<100 \%$ fruit juice.

${ }^{*}$ Parents who reported on the Household Survey that their children ate the foods at least once weekly.

tParents who reported that their children ate the foods $\geq 5$ times/week.

$\ddagger$ Reports from directors at the sixteen child-care centres where the Household Survey was administered.

§Proportion of centres that provided the selection of foods and beverages based on $1 \mathrm{~d}$ of direct observations of the lunch meal at each child-care centre.

\|Data were not collected or observed.

Third, beverages and foods offered to children at home were less healthful than beverages and foods offered to children at group child-care centres in NYC. In the present study, most parents reported that children drank high-fat milk (whole or $2 \%$ ) at home whereas low-fat milk ( $1 \%$ or skimmed) was offered at most child-care centres, as stated in formal nutrition policies in Article 47 of the NYC Health Code ${ }^{(44)}$. Other studies show that children of pre-school age tend to consume more high-fat than low-fat milk at home ${ }^{(45,46)}$, with factors such as low parental education, belief that high-fat milk is higher in $\mathrm{Ca}$ and healthier for pre-school children and parents not having tried low-fat milk contributing to this trend ${ }^{(45)}$. For pre-school children, low-fat milk is recommended because it contributes less fat, cholesterol and energy to the diet than whole or $2 \% \operatorname{milk}^{(46,47)}$. Children also drank fruit drinks and soft drinks and ate more desserts and sweet and salty snacks at home as opposed to consumption within the child-care setting. Fruit drinks and soft drinks have added sweeteners but provide little or no nutritional benefits $^{(48)}$. Moreover, excessive consumption of these beverages, as well as foods with high amounts of added sugars, is associated with increased risk of obesity ${ }^{(48-50)}$.

Children in the current study spent at least $8 \mathrm{~h} / \mathrm{d}$ in child-care centres. To meet daily nutrition needs, foods and beverages provided in both the home and child-care environment should be in accordance with current dietary guidelines $^{(51)}$. Although most parents reported providing fruits and vegetables to children frequently, they also provided less healthful foods such as fruit drinks, soft drinks, desserts and sweet and salty snacks. On average, the selection of foods and beverages provided at childcare centres appeared to be more healthful than those provided at home, although results from the larger study of forty child-care centres showed that most children's actual consumption at child-care centres was less than half of the daily food group recommendations, especially for vegetables, and was low for some nutrients, most notably vitamin $\mathrm{E}^{(27)}$. These findings underscore the need for nutrition policies and intervention strategies that promote healthy eating in children in both the home and child-care environment.

Although the current cross-sectional study provides data from a sizeable convenience sample, it is important to note that these findings may not be generalizable to or representative of all children and caregivers in NYC or elsewhere in the USA. Self-reported information from caregivers may not be accurate; however, prior studies report that parents tend to provide reliable information about their children's dietary intake at home ${ }^{(52-54)}$. Dietary data from $1 \mathrm{~d}$ site visits may not represent types or amounts of foods served to children every day, but the observed dietary intakes at the child-care centres were generally consistent with the reports from the directors. The Household Survey was not tested for reliability, but content validity was confirmed by a group of nutrition and public health experts. A complete $24 \mathrm{~h}$ record of children's dietary intakes was not possible because of expense. Also, the Household Survey may not have been completed by caregivers whose children were observed during mealtime in centre classrooms in the larger study. However, data were collected from multiple sources (i.e. surveys to parents and centre directors, and direct observation of lunch at centres). In addition, the sample of parents consisted of low- and middle-income families from diverse ethnic backgrounds. 
Building on the results of the study, and with consideration of the generalizability of results, future research in this area should include child-care centres in other geographic regions of $\mathrm{NYC}$, dietary data from more than $1 \mathrm{~d}$ of observations at child-care centres, dietary observations to validate food consumption within childcare centres and home observations to validate parental self-report.

\section{Conclusions}

Findings from the present study suggest that children's dietary intakes at home, especially with regard to beverages, need to be improved. Policy changes to child-care centres alone are not enough to alter the nutritional intake of young children. Given new nutrition standards across NYC child-care centres and the implementation of practices consistent with these standards (as evidenced in the larger study), there are opportunities for child-care centres to help alter caregiver purchasing and meal planning behaviours. For example, parents may be more likely to purchase and serve low-fat or non-fat milk if they understand that this is what their children are drinking every day at child care. Incorporating nutrition as part of regular classroom activities, using mealtimes to encourage children to try new foods and teach children about healthful eating habits, and organizing age-appropriate cooking activities at child-care centres may encourage children to adopt healthy eating behaviours. Families may also benefit from receiving education from nutrition professionals about the health risks and benefits of foods and the implications of food purchasing and consumption behaviours on children's dietary intakes and nutritional status. Although efforts such as the Let's Move! initiative, launched by the White House in $2010^{(55)}$, encourage parents to provide healthful foods and beverages to children at home, parents are likely to require more direct support for changing their daily interactions with their children at home. Information alone is unlikely to alter parenting behaviours that are related to unhealthful eating patterns, especially for caregivers living in stressful environments with limited resources. Programmes that support parenting behaviours and community efforts that encourage specific time- and cost-saving techniques for shopping, food preparation and storage of healthful foods and beverages that appeal to young children, as well as to the rest of the family, are required for lasting changes.

\section{Acknowledgements}

Funding for the study was provided from two contracts from the New York City Department of Health and Mental Hygiene. The project was carried out while T.O.E. was a doctoral candidate in the Department of Nutrition, Food
Studies and Public Health at New York University. The authors do not have any conflicts of interest to disclose. T.O.E. was the project coordinator for the larger project on nutrition practices at NYC child-care centres which housed the present study. She participated in the development of the Household Survey, data collection, data analysis and manuscript development. L.B.D. was the principal investigator for the larger project on nutrition practices at NYC child-care centres which housed the present study. She led the conceptualization of the study purpose and design, data collection and analysis, and provided guidance in developing the manuscript. She has seen and approved the contents of the submitted manuscript. C.Y. participated in the conceptualization of the study purpose, design and data collection. She has seen and approved the contents of the submitted manuscript. L.M.B. provided guidance during the various phases of the study, including development of the study purpose, data analysis and manuscript development. She has seen and approved the contents of the submitted manuscript. L.L.H. provided guidance during the various phases of the study, including development of the study purpose, data analysis and manuscript development. She has seen and approved the contents of the submitted manuscript. The authors would like to thank the parents and caregivers who completed the Household Survey; the directors and staff of the participating child-care centres; the colleagues who provided feedback on the materials; and the New York City Department of Health and Mental Hygiene who provided funding support for the study.

\section{References}

1. Birch LL \& Fisher JO (1998) Development of eating behaviors among children and adolescents. Pediatrics 101, 539-549.

2. Federal Interagency Forum on Child and Family Statistics (2009) America's Children: Key National Indicators of Well-being, 2009. Washington, DC: US Government Printing Office; available at http://www.childstats.gov/pdf/ ac2009/ac_09.pdf

3. Ball SC, Benjamin SE \& Ward DS (2008) Dietary intakes in North Carolina child-care centers: are children meeting current recommendations? J Am Diet Assoc 108, 718-721.

4. Padget A \& Briley ME (2005) Dietary intakes at child-care centers in Central Texas fail to meet Food Guide Pyramid recommendations. J Am Diet Assoc 105, 790-793.

5. Bollella MC, Spark A, Boccia LA et al. (1999) Nutrient intake of Head Start children: home vs. school. J Am Coll Nutr 18, 108-114.

6. Oakley CB, Bomba AK, Knight KB et al. (1995) Evaluation of menus planned in Mississippi child-care centers participating in the Child and Adult Care Food Program. $J$ Am Diet Assoc 95, 765-768.

7. Davison KK \& Birch LL (2001) Childhood overweight: a contextual model and recommendations for future research. Obes Rev 2, 159-171.

8. Cullen KW, Baranowski T, Owens E et al. (2003) Availability, accessibility, and preferences for fruit, $100 \%$ fruit juice, and vegetables influences children's dietary behavior. Health Educ Behav 30, 615-626. 
9. Haerens L, Craeynest M, Deforche B et al. (2008) The contribution of psychosocial and home environmental factors explaining eating behaviors in adolescents. Eur J Clin Nutr 62, 51-59.

10. Hanson NI, Neumark-Sztainer D, Eisenberg ME et al. (2005) Associations between parental report of the home food environment and adolescent intakes of fruits, vegetables and dairy foods. Public Health Nutr 8, 77-85.

11. Haapalahti M, Mykkanen H, Ikkanen S et al. (2003) Meal patterns and food use in 10- to 11-year old Finnish children. Public Health Nutr 6, 363-370.

12. Neumark-Sztainer D, Hannan PJ, Story M et al. (2003) Family meal patterns: associations with sociodemographic characteristics and improved dietary intake among adolescents. J Am Diet Assoc 103, 317-322.

13. Videon TM \& Manning CK (2003) Influences on adolescent eating patterns: the importance of family meals. J Adol Health 32, 365-373.

14. Gillman MW, Rifas-Shiman SL, Frazier AL et al. (2000) Family dinner and diet quality among older children and adolescents. Arch Fam Med 9, 235-240.

15. Taveras EM, Berkey CS, Rifas-Shiman SL et al. (2005) Association of consumption of fried food away from home with body mass index and diet quality in older children and adolescents. Pediatrics 116, 518-524.

16. Bowman SA, Gortmaker SL, Ebbeling CB et al. (2004) Effects of fast food consumption on energy intake and diet quality among children in a national household survey. Pediatrics 113, 112-118.

17. Befort C, Kaur H, Nollen N et al. (2006) Fruit, vegetable, and fat intake among non-Hispanic black and white adolescents: associations with home food availability and food consumption settings. J Am Diet Assoc 106, 367-373.

18. Paeratakul S, Ferdinand DP, Champagne CM et al. (2003) Fast food consumption among US adults and children: dietary and nutrient intake profile. J Am Diet Assoc 103, $1332-1338$

19. Matheson DM, Wang Y, Klesges LM et al. (2004) AfricanAmerican girls' dietary intake while watching television. Obes Res 12, Suppl., 32S-37S.

20. Marquis M, Filion YP \& Dagenais F (2005) Does eating while watching television influence children's food related behaviors? Can J Diet Pract Res 66, 12-18.

21. Feldman S, Eisenberg ME, Neumark-Sztainer D et al. (2007) Associations between watching TV during family meals and dietary intake among adolescents. J Nutr Educ Behav 39, 257-263.

22. Coon KA, Goldberg J, Rogers BL et al. (2001) Relationships between use of television during meals and children's food consumption patterns. Pediatrics 107, E7.

23. Spurrier NJ, Magarey AA, Golley R et al. (2008) Relationships between the home environment and physical activity and dietary patterns of preschool children: a cross-sectional study. Int J Behav Nutr Phys Act 5, 31.

24. Ventura AK \& Birch LL (2008) Does parenting affect children's eating and weight status? Int J Behav Nutr Phys Act 5, 15.

25. White House Task Force on Childhood Obesity Report to the President (2010) Solving the problem of childhood obesity within a generation. http://www.letsmove.gov/ sites/letsmove.gov/files/TaskForce_on_Childhood_Obesity_ May2010_FullReport.pdf (accessed April 2011).

26. Erinosho $T$ (2008) Nutrition policies and practices of New York City daycare centers and the dietary behaviors of children who attend the daycare centers. PhD Dissertation, New York University (publication no. AAT 3332506).

27. Erinosho TO, Dixon LB, Young C et al. (2011) Nutrition practices of 40 childcare centers in New York City are positive but children's dietary intakes need improvement. J Am Diet Assoc 111, 1391-1397.
28. US Department of Health and Human Services \& US Department of Agriculture (2005) Dietary Guidelines for Americans, 2005. http://www.health.gov/dietaryguidelines/ (accessed December 2010).

29. Timperio A, Ball K, Roberts R et al. (2008) Children's fruit and vegetable intake: associations with the neighborhood food environment. Prev Med 46, 331-335.

30. Rose D \& Richards R (2004) Food store access and household fruit and vegetable use among participants in the US Food Stamp Program. Public Health Nutr 7, 1081-1088.

31. Bodor JN, Rose D, Farley TA et al. (2008) Neighborhood fruit and vegetable availability and consumption: the role of small food stores in an urban environment. Public Health Nutr 11, 413-420.

32. Pearce J, Hiscock R, Blakely T et al. (2008) The contextual effects of neighborhood access to supermarkets and convenience stores on individual fruit and vegetable consumption. J Epidemiol Community Health 62, 198-201.

33. Herman DR, Harrison GG, Afifi AA et al. (2008) Effect of a targeted subsidy on intake of fruits and vegetables among low-income women in the Special Supplemental Nutrition Program for Women, Infants, and Children. Am J Public Health 98, 98-105.

34. Anderson JV, Bybee DI, Brown RM et al. (2001) 5 A Day fruit and vegetable intervention improves consumption in a low income population. J Am Diet Assoc 101, 195-202.

35. McCormack LA, Laska MN, Larson NI et al. (2010) Review of the nutrition implications of farmers' markets and community gardens: a call for evaluation and research efforts. J Am Diet Assoc 110, 399-408.

36. Crawford D, Ball K, Mishra G et al. (2007) Which foodrelated behaviors are associated with healthier intakes of fruits and vegetables among women? Public Health Nutr 10, 256-265.

37. Anderson PM \& Butcher KF (2006) Childhood obesity: trends and potential causes. Future Child 16, 19-45.

38. Lin B, Guthrie J \& Blaylock JR (1996) The Diets of America's Children: Influence of Dining Out, Household Characteristics, and Nutrition Knowledge. http://www.ers.usda.gov/ Publications/AER746/ (accessed March 2011).

39. Adair LS \& Popkin B (2005) Are child eating patterns being transformed globally? Obes Res 13, 1281-1299.

40. Guthrie JF, Lin BH \& Frazao E (2002) Role of food prepared away from home in the American diet, 1977-78 versus 1994-96: changes and consequences. J Nutr Educ Behav 34, 140-150.

41. Poti JM \& Popkin BM (2011) Trends in energy intake among US children by eating location and food source, 1977-2006. J Am Diet Assoc 111, 1156-1164.

42. Jeffery RW, Baxter J, McGuire M et al. (2006) Are fast food restaurants an environmental risk factor for obesity? Int $J$ Behav Nutr Phys Act 3, 2

43. Francis LA \& Birch LL (2006) Does eating during television viewing affect preschool children's intake? J Am Diet Assoc 106, 598-600.

44. New York City Department of Health and Mental Hygiene (2007) Notice of adoption of the repeal and reenactment of Article 47 of the New York City Health Code. http://www. nyc.gov/html/doh/downloads/pdf/public/notice-adoptionhc-art47-0308.pdf (accessed April 2011).

45. Dennison BA, Erb TA \& Jenkins PL (2001) Predictors of dietary milk fat intake by preschool children. Prev Med 33, 536-542.

46. Kranz S, Lin P \& Wagstaff DA (2007) Children's dairy intake in the United States: too little, too fat? J Pediatr 151, 642-646.

47. Lee HHC, Gerrior SA \& Smith JA (1998) Energy, macronutrient, and food intakes in relation to energy compensation in consumers who drink different types of milk. Am J Clin Nutr 67, 616-623. 
48. American Academy of Pediatrics Committee on Nutrition (2001) The use and misuse of fruit juice in pediatrics. Pediatrics 107, 1210-1213.

49. Dubois L, Farmer A, Girard M et al. (2007) Regular sugarsweetened beverage consumption between meals increases risk of overweight among preschool-aged children. $J \mathrm{Am}$ Diet Assoc 107, 924-934.

50. Ludwig DS, Peterson KE \& Gortmaker SL (2001) Relation between consumption of sugar-sweetened drinks and childhood obesity: a prospective, observational analysis. Lancet 357, 505-508.

51. US Department of Agriculture (2010) Dietary Guidelines for Americans, 2010. http://www.cnpp.usda.gov/DGAs2010PolicyDocument.htm (accessed March 2011).
52. Basch CE, Shea S, Arliss R et al. (1990) Validation of mothers' reports of dietary intake by four to seven year-old children. Am J Public Health 80, 1314-1317.

53. Eck LH, Klesges RC \& Hanson CL (1989) Recall of a child's intake from one meal: are parents accurate? J Am Diet Assoc 89, 784-789.

54. Klesges RC, Hanson CL, Eck LH et al. (1988) Accuracy of self-reports of food intake in obese and normal weight individuals: effects of parental obesity on reports of children's dietary intake. Am J Clin Nutr $\mathbf{4 8}$, $1252-1256$.

55. Let's Move! (2011) America's move to raise a healthier generation of kids. http://www.letsmove.gov/eathealthy. php (accessed March 2011). 